\title{
Evaluation of Ventilators Used During Transport of Critically Ill Patients: A Bench Study
}

\author{
Salah Boussen PhD MD, Marc Gainnier PhD MD, and Pierre Michelet PhD MD
}

\begin{abstract}
OBJECTIVE: To evaluate the most recent transport ventilators' operational performance regarding volume delivery in controlled mode, trigger function, and the quality of pressurization in pressure support mode. METHODS: Eight recent transport ventilators were included in a bench study in order to evaluate their accuracy to deliver a set tidal volume under normal resistance and compliance conditions, ARDS conditions, and obstructive conditions. The performance of the triggering system was assessed by the measure of the decrease in pressure and the time delay required to open the inspiratory valve. The quality of pressurization was obtained by computing the integral of the pressure-time curve for the first $300 \mathrm{~ms}$ and $500 \mathrm{~ms}$ after the onset of inspiration. RESULTS: For the targeted tidal volumes of 300,500 , and $800 \mathrm{~mL}$ the errors ranged from $-3 \%$ to $48 \%,-7 \%$ to $18 \%$, and $-5 \%$ to $25 \%$ in the normal conditions, $-4 \%$ to $27 \%,-2 \%$ to $35 \%$, and $-3 \%$ to $35 \%$ in the ARDS conditions, and $-4 \%$ to $53 \%,-6 \%$ to $30 \%$, and $-30 \%$ to $28 \%$ in the obstructive conditions. In pressure support mode the pressure drop range was $0.4-1.7 \mathrm{~cm} \mathrm{H}_{2} \mathrm{O}$, the trigger delay range was $68-198 \mathrm{~ms}$, and the pressurization performance (percent of ideal pressurization, as measured by pressure-time product at $300 \mathrm{~ms}$ and $500 \mathrm{~ms}$ ) ranges were $-9 \%$ to $44 \%$ at $300 \mathrm{~ms}$ and $6 \%-66 \%$ at $500 \mathrm{~ms}(P<.01)$. CONCLUSIONS: There were important differences in the performance of the tested ventilators. The most recent turbine ventilators outperformed the pneumatic ventilators. The best performers among the turbine ventilators proved comparable to modern ICU ventilators. Key words: mechanical ventilation; transport ventilator; bench study; ICU patient transport; pressure support ventilation; inspiratory trigger; ventilator performances. [Respir Care 2013;58(11): 1911-1922. (C) 2013 Daedalus Enterprises]
\end{abstract}

\section{Introduction}

Transport ventilators are designed to transport critically ill patients from the ICU to the radiology department, the operating room, from the point of care by the emergency team to the ICU, or from one hospital location to another. ${ }^{1}$ The manufacturers regularly update and upgrade their machines with improvements in technology, in response to

The authors are affiliated with Réanimation des Urgences et Médicale, Hôpital de la Timone, Marseille, France.

Dr Michelet has disclosed a relationship with Air Liquide. The other authors have disclosed no conflicts of interest.

Correspondence: Salah Boussen PhD MD, Réanimation des Urgences et Médicale, Hôpital de la Timone, 254 Rue Saint Pierre, Marseille, 13005 France. E-mail: michelsalah.boussen@ap-hm.fr.

DOI: $10.4187 /$ respcare. 02144 feedback from users, published data, and for commercial reasons. To our knowledge, few studies have been published that specifically evaluate transport ventilators. One such study published, in 2002, compared 5 transport ventilators. ${ }^{2}$ Chipman et al performed the most recent and largest, in 2007. ${ }^{3}$ They evaluated 15 transport ventilators, most of which are sold on the American market. Some other studies looked at the performance of transport ventilators during patient triggered ventilation ${ }^{4}$ or volume controlled mode..$^{5}$ At present, there are mainly 2 categories of transport ventilator available on the market: pneumatic and turbine. Pneumatic ventilators use compressed oxygen for power, and their performance highly depends on the pressure in the oxygen tank. The second category of transport ventilators, more recently available to clinicians, is based on a different technology inspired by home-care ventilators. They use an electrically powered turbine to generate pressure. Their performance, particularly those of the last generation, seems to be very similar to those of 


\section{Evaluation of Ventilators Used During Transport of Critically Ill Patients}

intensive care ventilators, but is highly dependent on the internal battery duration. Other than these 2 main categories, the compressor driven ventilator is a less frequent solution.

The purpose of this bench study was to evaluate the performance of transport ventilators recently placed on the market, by comparing their performances with that of older ones.

\section{Methods}

\section{Ventilators Tested}

We tested 8 portable ventilators: Osiris 3 (Air Liquide Medical System, Paris, France), Monnal T60 (Air Liquide Medical System, Paris, France); Oxylog 3000+ (Dräger Medical, Lübeck, Germany), Carina (Dräger Medical, Lübeck, Germany), Elisée 350 (ResMed, San Diego, California), Medumat Transport WM28400 with $\mathrm{CO}_{2}$ measurement WM28400 (Weinmann Medical Technology, Hamburg, Germany), Hamilton C1 (Hamilton Medical, Reno, Nevada), and Hamilton T1 (Hamilton Medical, Reno, Nevada). The ventilators were provided by the manufacturers or loaned from another ICU. The main characteristics of the 8 ventilators are listed in Table 1. The Hamilton $\mathrm{C} 1$ is a compact, mid-level ICU ventilator. The Hamilton T1 is its transportable version. The Monnal T60 was still under development at the time of the test. Three of the tested ventilators are pneumatic (Oxylog 3000+, Medumat, and Osiris 3), while all the others are turbine ventilators.

\section{Experimental Setup}

The experimental setup, very similar to the one used in previous research, ${ }^{2}$ (Fig. 1) included the following elements:

- A dual-chamber test lung (TTL 1600, Michigan Instruments, Grand Rapids, Michigan)

- A pneumotachograph attached to a differential pressure transducer (TSD 160A [ $\pm 2.5 \mathrm{~cm} \mathrm{H}_{2} \mathrm{O}$ ], Biopac Systems, Goleta, California) for measurement of air flow

- A side-port connected to a pressure transducer (TSD104 [-50 to $300 \mathrm{~cm} \mathrm{H}_{2} \mathrm{O}$ ], Biopac Systems, Goleta, California) for pressure measurement

- An oxygen paramagnetic sensor, with a response time of about 10 s (5120, Datex-Ohmeda/GE Healthcare, Madison, Wisconsin)

- The ventilator to be tested

Before each experiment, the pneumotachograph and the pressure transducer were calibrated with an ICU ventilator

\section{QUICK LOOK}

\section{Current knowledge}

Transport of mechanically ventilated patients for tests and therapy is common. Ventilators used for transport must support gas exchange and decrease the work of breathing while being lightweight, rugged, and with long battery duration.

\section{What this paper contributes to our knowledge}

In the 8 ventilators tested there were important differences in performance. The turbine-powered ventilators outperformed the pneumatic ventilators in tidal volume accuracy and triggering performance. Several of the turbine ventilators had performance comparable to ICU ventilators.

(PB840, Puritan Bennett, Pleasanton, California) operating in ambient-temperature-and-pressure-dry conditions. The flow transducer was calibrated at 0 and $0.25 \mathrm{~L} / \mathrm{s}$, at constant flow in volume controlled mode. The calibration of the pneumotachograph was then checked by measuring a known volume administered through the pneumotachograph via a 1-L super syringe. The pressure transducer was calibrated with the PB840, with zero PEEP and $10 \mathrm{~cm} \mathrm{H}_{2} \mathrm{O}$ of PEEP. The calibration accuracy of the pressure transducer was checked by measuring a known pressure of $10 \mathrm{~cm} \mathrm{H}_{2} \mathrm{O}$ with a water column.

During the experiments, the flow and pressure signals were acquired with an analog-to-digital converter (MP100, Biopac Systems, Goleta, California). The volume was obtained by integrating the flow signal. The acquisition frequency of all the signals was set at $200 \mathrm{~Hz}$. All data were stored in a computer for subsequent analysis (Acqknowledge software, Biopac Systems, Goleta, California).

\section{Protocol}

We tested all the ventilators in both static and dynamic conditions. $\mathrm{F}_{\mathrm{IO}_{2}}$ was monitored throughout the experiment.

\section{Static Conditions}

This situation corresponds to a passively ventilated patient. The performances while delivering a set volume were assessed with the test lung connected to the ventilator tested (see Fig. 1) under 3 different conditions:

- Normal resistance $\left(5 \mathrm{~cm} \mathrm{H}_{2} \mathrm{O} / \mathrm{L} / \mathrm{s}\right)$ and compliance $\left(100 \mathrm{~mL} / \mathrm{cm} \mathrm{H}_{2} \mathrm{O}\right)$ 


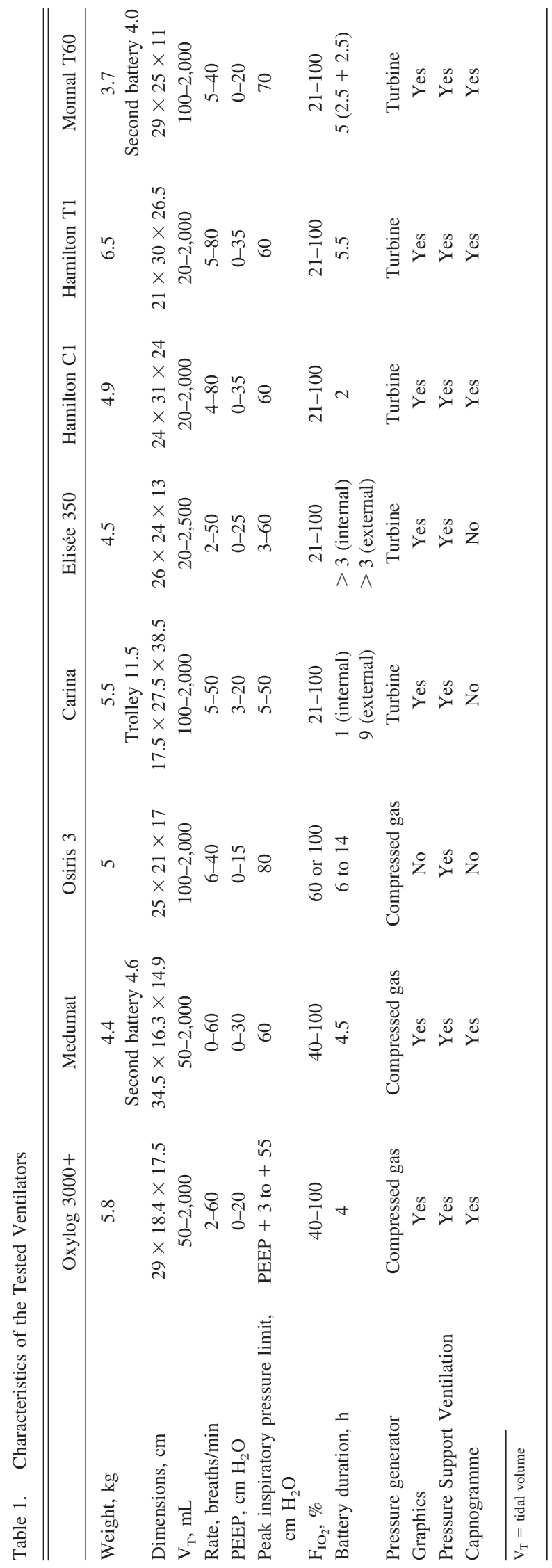

- ARDS: high resistance $\left(20 \mathrm{~cm} \mathrm{H}_{2} \mathrm{O} / \mathrm{L} / \mathrm{s}\right)$ and low compliance $\left(30 \mathrm{~mL} / \mathrm{cm} \mathrm{H}_{2} \mathrm{O}\right)$

- Airway obstruction: very high resistance $\left(50 \mathrm{~cm} \mathrm{H}_{2} \mathrm{O} /\right.$ $\mathrm{L} / \mathrm{s})$ and normal compliance $\left(100 \mathrm{~mL} / \mathrm{cm} \mathrm{H}_{2} \mathrm{O}\right)$

Very high, high, and normal resistances were achieved with resistors (Pneuflo Rp50, Rp20, and Rp5, Michigan Instruments, Grand Rapids, Michigan). All the ventilators were operated according to the manufacturer's instructions, taking into account the circuit compliance correction algorithm if one was available.

\section{Gas Consumption and Battery Duration Testing}

For both gas consumption and battery duration testing, the ventilators were set to deliver a tidal volume $\left(\mathrm{V}_{\mathrm{T}}\right)$ of $500 \mathrm{~mL}$ with a PEEP of $5 \mathrm{~cm} \mathrm{H}_{2} \mathrm{O}$ and a respiratory frequency of 12 breaths/min under the normal condition.

Gas consumption was defined as the time during which ventilators could operate with an $\mathrm{F}_{\mathrm{IO}_{2}}$ of 1.0 with a $5-\mathrm{L}$ oxygen cylinder (2,900 psig, 1,000 $\mathrm{L}$ of oxygen). The $\mathrm{V}_{\mathrm{T}}$ was recorded when the pressure in the oxygen cylinder was near 2,900 psig, then 1,450 psig, then $<725$ psig (with the battery fully charged).

The battery duration was defined as the time during which the ventilator functioned, starting with a fully charged battery, at the minimal $\mathrm{F}_{\mathrm{IO}_{2}}$ adjustable on each ventilator, to limit oxygen consumption.

\section{Tidal Volume}

With 5 of the ventilators, $\mathrm{V}_{\mathrm{T}}$ is delivered with a constant flow during volume controlled mode. For the other 3 (Carina, Hamilton C1, and Hamilton T1), the "volume controlled mode" is actually similar to a pressure controlled mode with a target $\mathrm{V}_{\mathrm{T}}$ (dual mode). With all the ventilators tested, the breathing frequency was set at 20 breaths/min, and the inspiratory time was $1 \mathrm{~s}$. All the ventilators were operated at zero PEEP or the minimal PEEP.

We tested $\mathrm{V}_{\mathrm{T}}$ of 300,500 , and $800 \mathrm{~mL}$. The measured $\mathrm{V}_{\mathrm{T}}$ values were averaged over 40 breaths. Breath-to-breath variability in delivered $\mathrm{V}_{\mathrm{T}}$ for each individual ventilator was computed as the difference between 2 consecutives breaths:

$$
\left(\mathrm{V}_{\mathrm{T}}(\mathrm{T}+1)-\mathrm{V}_{\mathrm{T}}(\mathrm{T})\right) / \mathrm{V}(\mathrm{T})
$$

where $\mathrm{T}$ is the duration of the breathing cycle. A plateau time of $10 \%$ was applied if the setting was available on the ventilator. 


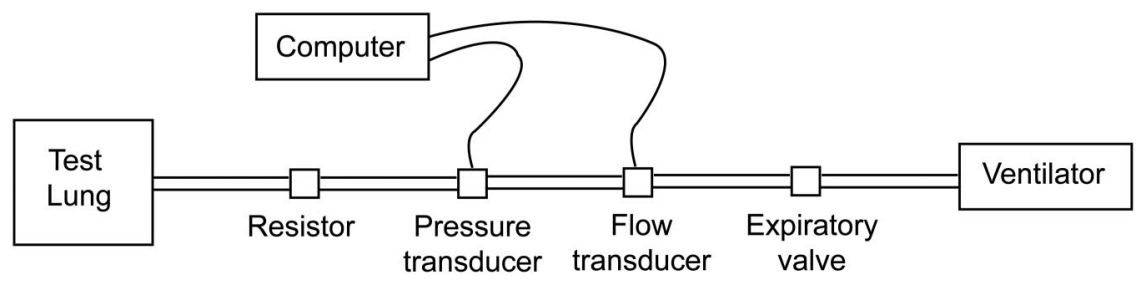

Fig. 1. Experimental setup for the static experiments.

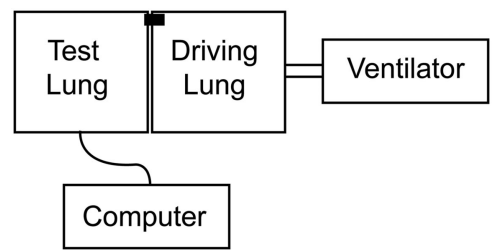

Fig. 2. Experimental setup for the dynamic experiments. The 2 test lung compartments were attached with a metal clip.

\section{Dynamic Conditions}

Spontaneous ventilation is a major issue during transport of a conscious or moderately sedated, mechanically ventilated patient within and between hospitals. ${ }^{6}$ Hence, we also tested these ventilators in an experimental situation simulating spontaneous ventilation, to assess the trigger sensitivity of the inspiratory valves and their ability to pressurize the respiratory system.

The experimental setup is shown in Figure 2. One chamber of the test lung (the driving lung) was connected to the PB840 ventilator, set in volume controlled mode with constant flow. The respiratory frequency was set at 12 breaths/ min, with a fixed inspiration time of $20 \%$ of the total respiratory cycle time. The other test lung chamber (the experimental lung) was connected to the ventilator being tested. Compliance values of $30 \mathrm{~mL} / \mathrm{cm} \mathrm{H}_{2} \mathrm{O}$ and of $80 \mathrm{~mL} /$ $\mathrm{cm} \mathrm{H}_{2} \mathrm{O}$ were adjusted to the driving and experimental lungs. The lung-coupling clip of the model connected the 2 chambers. A positive pressure created in the driving lung induced a negative relative pressure in the experimental lung, which triggered the ventilator being tested. Since the compliance of the 2 lung compartments was different, it was necessary to apply PEEP to the driving lung to obtain a perfect contact of the metal clip between the 2 chambers at the end of expiration. The triggering system of the tested ventilator was set at the maximal sensitivity and was not changed, even in case of auto-triggering.

Each ventilator was tested during pressure support ventilation (PSV), at pressure support of 10 and $15 \mathrm{~cm} \mathrm{H}_{2} \mathrm{O}$, with and without $5 \mathrm{~cm} \mathrm{H}_{2} \mathrm{O}$ PEEP. Rise time and triggering sensitivity were set to the fastest time and most sensitive, respectively, and evaluated at 2 levels of simulated inspiratory effort (normal and strong). To simulate different magnitudes of inspiratory effort, the $\mathrm{V}_{\mathrm{T}}$ of the driving ventilator was set at 220 and $440 \mathrm{~mL}$, with a fixed inspiratory time of $1 \mathrm{~s}$ (corresponding to flows of $0.22 \mathrm{~L} / \mathrm{s}$ and $0.44 \mathrm{~L} / \mathrm{s}$, respectively). The corresponding effort intensity was measured as the pressure drop at $0.1 \mathrm{~s}$ after the beginning of inspiration $\left(\mathrm{P}_{0.1}\right)$, at the exit of the tested chamber. This $\mathrm{P}_{0.1}$ was equal to $2 \mathrm{~cm} \mathrm{H}_{2} \mathrm{O}$ (normal effort) or $4 \mathrm{~cm} \mathrm{H}_{2} \mathrm{O}$ (strong effort). $\mathrm{P}_{0.1}$ is about $2 \mathrm{~cm} \mathrm{H}_{2} \mathrm{O}$ during normal effort by healthy persons and during full assistance, ${ }^{7}$ whereas a very strong effort by a patient with acute respiratory failure can generate a $\mathrm{P}_{0.1}$ of $>10 \mathrm{~cm} \mathrm{H}_{2} \mathrm{O}{ }^{7}$

We measured the pressure reduction $(\Delta \mathrm{P})$ and the time delay required to open the inspiratory valve (Fig. 3). These measurements were made at $\mathrm{F}_{\mathrm{IO}_{2}} 0.6$ with all the ventilators except the Osiris 3, with which these measurements were at an $\mathrm{F}_{\mathrm{IO}_{2}}$ of 1.0.

To assess pressurization performance, we computed the pressure-time product (PTP), as area under or above the base line pressure (zero PEEP or PEEP) on the pressuretime curve during the first $300 \mathrm{~ms}$ (PTP300) and $500 \mathrm{~ms}$ (PTP500) after the beginning of inspiratory effort (see Fig. 3). The triggering phase represents only a part of the total inspiratory effort and is shorter than the pressurization phase. PTP is expressed as a percentage of the ideal pressure-time product. The ideal PTP can be calculated by the product of time ( $\mathrm{T}=0.3 \mathrm{~s}$ or $0.5 \mathrm{~s})$ by the PSV level. ${ }^{8}$ PTP500 is better to evaluate pressurization performance than PTP300, which is more influenced by trigger performance.

\section{Comparison Between Gas Powered and Turbine Ventilators}

We computed the average error for each $V_{T}$ in each test condition for all the ventilators. We then performed a statistical comparison between the 2 groups.

To evaluate trigger performance we computed the average PTP in each condition (minimal PEEP and $5 \mathrm{~cm} \mathrm{H}_{2} \mathrm{O}$ PEEP, strong and weak inspiratory effort), and the average PTP300 and the PTP500 of each inspiratory effort with all the ventilators. 

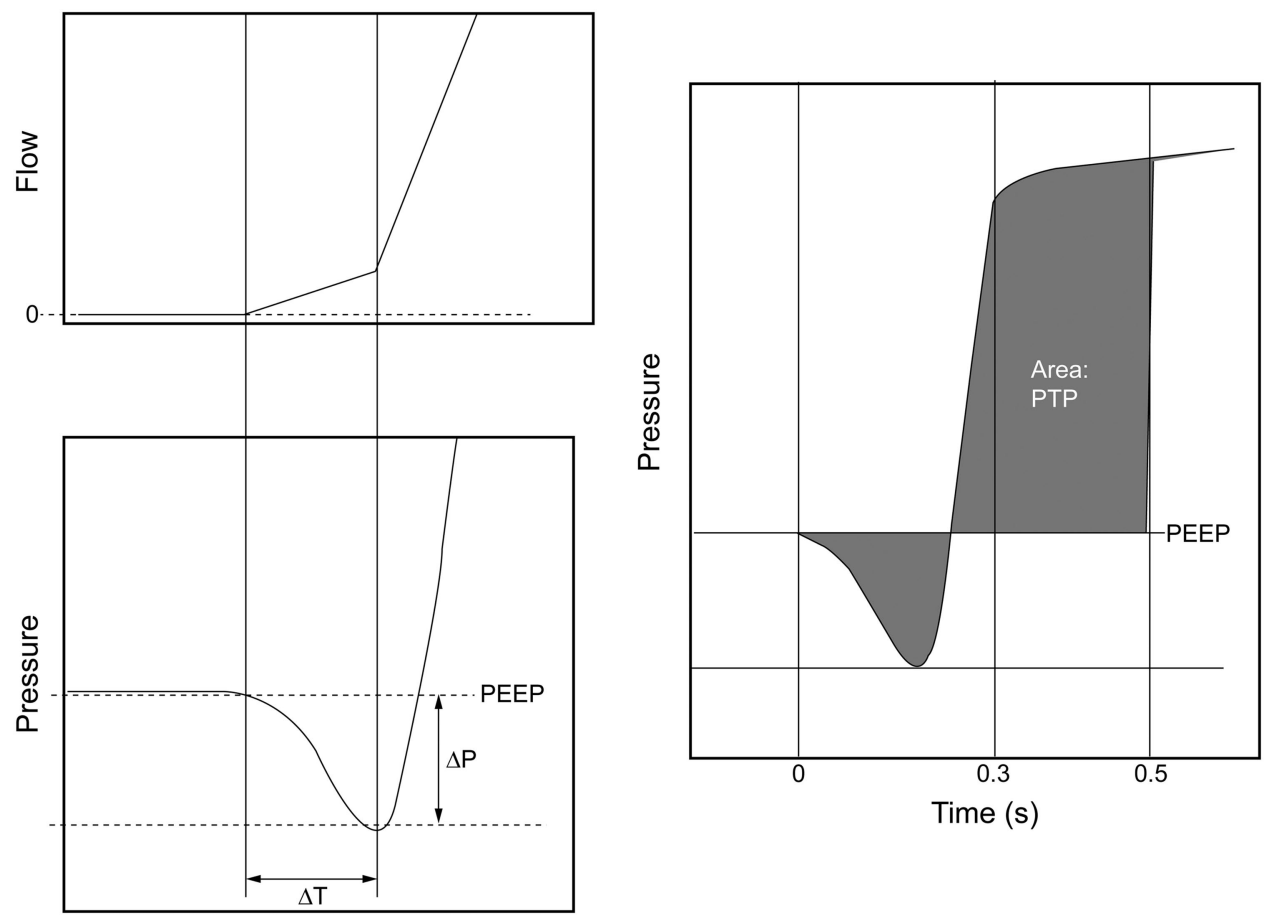

Fig. 3. Schematic of ventilator triggering assessment. $\Delta \mathrm{P}=$ pressure change required to open the inspiratory valve. $\Delta \mathrm{T}=$ time delay until the opening of the valve. PTP = pressure-time product. The PTP300 and PTP500 signals are the net area under the pressure curve for the first $300 \mathrm{~ms}$ and $500 \mathrm{~ms}$, respectively. The measured PEEP is subtracted before integration of the pressure-time curve.

\section{Statistical Analysis}

Each variable value represents the mean of values measured in a steady state. For $\mathrm{V}_{\mathrm{T}}$ we calculated the mean of 40 consecutive breaths at the steady state. For the dynamic measurements, each parameter represents the mean of 10 consecutives breaths at the steady state. All results are expressed as mean and $99 \%$ confidence interval. For comparative analysis we used one-way analysis of variance on ranks (Kruskal-Wallis test). $P<.05$ was considered statistically significant. For our analyses we used statistics software (SigmaStat 3.5, Systat Software/Cranes Software, Chicago, Illinois).

\section{Results}

\section{Gas Consumption and Battery Duration}

The results of gas consumption and battery duration are summarized in Table 2. The Elisée 350 was tested with a single battery. It has an external battery with the same characteristics as the internal battery. With 6 of the ventilators we found no $\mathrm{V}_{\mathrm{T}}$ variation during the battery duration or the oxygen tank duration. These ventilators seemed to stop before any malfunction occurred. The battery duration of 6 of the ventilators was longer than the manufacturer's specification.
Table 2. Battery Duration, Oxygen Tank Duration, and $\mathrm{V}_{\mathrm{T}}$ Change

\begin{tabular}{lcccc}
\hline \hline & $\begin{array}{c}\text { Battery } \\
\text { Duration } \\
\text { (h:min) }\end{array}$ & $\begin{array}{c}\text { Oxygen Tank } \\
\text { Duration } \\
\text { (h:min) }\end{array}$ & $\begin{array}{c}\mathrm{V}_{\mathrm{T}} \text { Change } \\
\text { During } \\
\text { Battery } \\
\text { Duration } \\
(\%)\end{array}$ & $\begin{array}{c}\mathrm{V}_{\mathrm{T}} \text { Change } \\
\text { During } \\
\text { Oxygen }\end{array}$ \\
$\begin{array}{llccc}\text { Tank Duration } \\
(\%)\end{array}$ \\
\hline Oxylog 3000+ & $7: 25$ & $3: 00$ & $<1$ & $<1$ \\
Medumat & $6: 15$ & $1: 30$ & 5 & 20 \\
Osiris 3 & $6: 35$ & $2: 15$ & $<10$ & 25 \\
Carina & $1: 20$ & $2: 45$ & $<1$ & $<1$ \\
Elisée 350 & $5: 45^{*}$ & $2: 45$ & $<1$ & $<1$ \\
Hamilton T1 & $6: 10$ & $2: 20$ & $<1$ & $<1$ \\
Hamilton C1 & $2: 30$ & $2: 25$ & $<1$ & $<1$ \\
Monnal T60 & $6: 00$ & $2: 20$ & $<1$ & $<1$
\end{tabular}

* Elisée 350 was tested with a single internal battery.

Gas consumption was homogenous and near the ideal gas consumption, except for 2 pneumatic ventilators: with the Medumat and Osiris 3 the $\mathrm{V}_{\mathrm{T}}$ decreased with a low oxygen cylinder pressure.

\section{Tidal Volume}

Figure 4 shows the breath-to-breath $\mathrm{V}_{\mathrm{T}}$ variability, and Table 3 shows the $V_{T}$ measurements and error ranges. In the normal condition, 5 ventilators had a $<10 \%$ error at each 

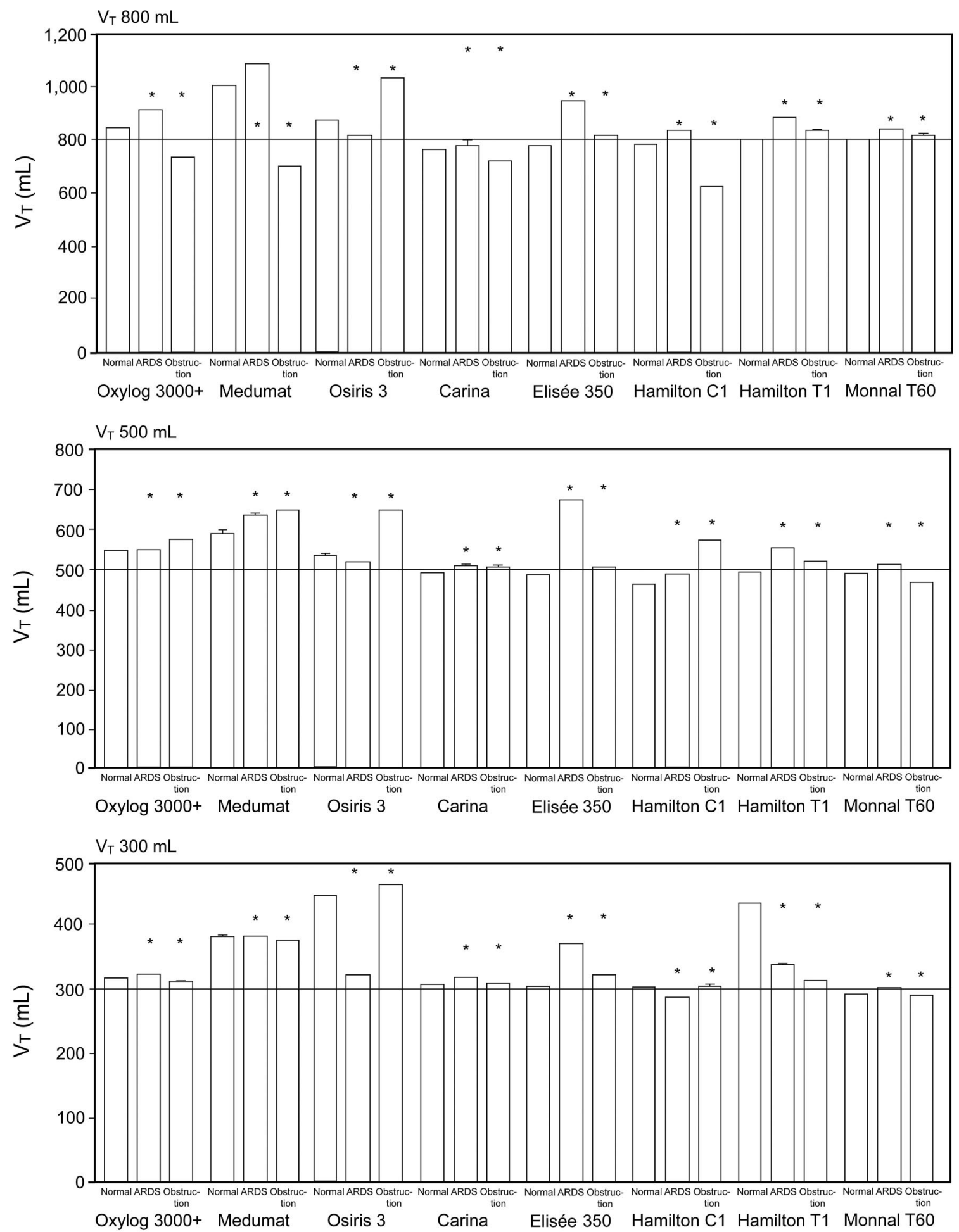

Fig. 4. Mean measured tidal volume $\left(V_{T}\right)$ delivered from the ventilators during 3 simulated respiratory conditions (normal, ARDS, and obstruction) and set tidal volume $\left(\mathrm{V}_{\mathrm{T}}\right)$ of $800 \mathrm{~mL}, 500 \mathrm{~mL}$, and $300 \mathrm{~mL}$. The whisker bars represent the $99 \%$ confidence intervals. ${ }^{*} P<.05$ versus the normal respiratory condition. 
Table 3. $\mathrm{V}_{\mathrm{T}}$ Measurements

\begin{tabular}{llc}
\hline \hline & $\begin{array}{c}\text { Mean } \\
\text { Measured } \\
\mathrm{V}_{\mathrm{T}} \text { Range } \mathrm{mL}\end{array}$ & $\begin{array}{c}\text { Error } \\
\text { Range*\% }\end{array}$ \\
\hline $\begin{array}{l}\text { Normal condition } \\
\text { Target } \mathrm{V}_{\mathrm{T}}, \mathrm{mL}\end{array}$ & \\
$\quad 300$ & $291-445$ & -3 to 48 \\
500 & $465-590$ & -7 to 18 \\
800 & $762-1000$ & -5 to 25 \\
ARDS condition & & -4 to 27 \\
Target $\mathrm{V}_{\mathrm{T}}, \mathrm{mL}$ & & -2 to 35 \\
300 & $287-382$ & -3 to 35 \\
500 & $491-673$ & \\
800 & $774-1080$ & -4 to 53 \\
Obstruction condition & & -6 to 30 \\
Target $\mathrm{V}_{\mathrm{T}}, \mathrm{mL}$ & & -30 to 28 \\
300 & $289-460$ & \\
500 & $469-650$ & \\
800 & $559-1021$ & \\
\hline * Relative to target volume. & & \\
\hline
\end{tabular}

targeted volume: Oxylog 3000+, Carina, Elisée 350, Hamilton C1, and Monnal T60. Surprisingly, the Hamilton T1 was unable to deliver an accurate $\mathrm{V}_{\mathrm{T}}$ of $300 \mathrm{~mL}$ in the normal condition. In the ARDS condition, 4 ventilators had a $<10 \%$ average $\mathrm{V}_{\mathrm{T}}$ error: Carina, Osiris 3, Hamilton $\mathrm{C} 1$, and Monnal T60. In the obstructive condition, 5 ventilators had a $<10 \%$ average $\mathrm{V}_{\mathrm{T}}$ error: Oxylog 3000+, Carina, Elisée 350, Hamilton C1, Hamilton T1, and Monnal T60. However, at $\mathrm{V}_{\mathrm{T}} 800 \mathrm{~mL}$ the Carina and Hamilton $\mathrm{C} 1$ failed to deliver the set $\mathrm{V}_{\mathrm{T}}$, due to the upper pressure limit.

The average breath-to-breath variability was $<1 \%$ for all the ventilators except the Medumat Transport WM28400 (Fig. 5). However, it took approximately 10 breaths to obtain $\mathrm{V}_{\mathrm{T}}$ stabilization with the Carina, Hamilton $\mathrm{T} 1$, and Hamilton $\mathrm{C} 1$.
We found no significant $\mathrm{F}_{\mathrm{IO}_{2}}$ variation during these experiments, even during the highest mechanical load.

\section{Dynamic Measurements}

The Carina could not deliver zero PEEP, so it was operated at its minimal PEEP for the first set of measurements. We measured a minimal PEEP of $2.8 \pm 0.1 \mathrm{~cm} \mathrm{H}_{2} \mathrm{O}$ for a minimal PEEP setting of $3 \mathrm{~cm} \mathrm{H}_{2} \mathrm{O}$. We found no significant $\mathrm{F}_{\mathrm{IO}_{2}}$ variation during these experiments, even during strong inspiratory efforts. The indices of inspiratory effort required to open the demand valve are shown in Figure 6.

\section{Inspiratory Trigger}

All the turbine-based ventilators had a trigger delay of $<120$ ms (Carina, Elisée 350, Hamilton C1, Hamilton T1, and Monnal T60). For these ventilators we found no significant variations in the trigger delay at the different PEEP levels, regardless of the inspiratory effort. Averaging all conditions, the mean trigger delay was between $68 \mathrm{~ms}$ and $198 \mathrm{~ms}$ (median $111 \mathrm{~ms}$ ).

\section{Pressurization Performance: $\Delta \mathrm{P}$ and PTP}

The pressure drop $(\Delta \mathrm{P})$ required to open the inspiratory valve differed among the ventilators. The mean $\Delta \mathrm{P}$ was $1.1 \mathrm{~cm} \mathrm{H}_{2} \mathrm{O}\left(0.4-1.7 \mathrm{~cm} \mathrm{H}_{2} \mathrm{O}\right)$. Five ventilators had an average $\Delta \mathrm{P}$ of $<1.0 \mathrm{~cm} \mathrm{H}_{2} \mathrm{O}$ (Carina, Elisée 350, Hamilton C1, Hamilton T1, and Monnal T60).

Figure 7 shows the PTP300 and PTP500 values. At the 2 pressure support levels studied (10 and $15 \mathrm{~cm} \mathrm{H}_{2} \mathrm{O}$ ), we found large differences in pressurization performance among the ventilators. The PTP300 percent-of-ideal-pressurization with the normal inspiratory effort ranged from $-9 \%$ to $44 \%$, and at PTP500 it ranged from $6 \%$ to $66 \%$.

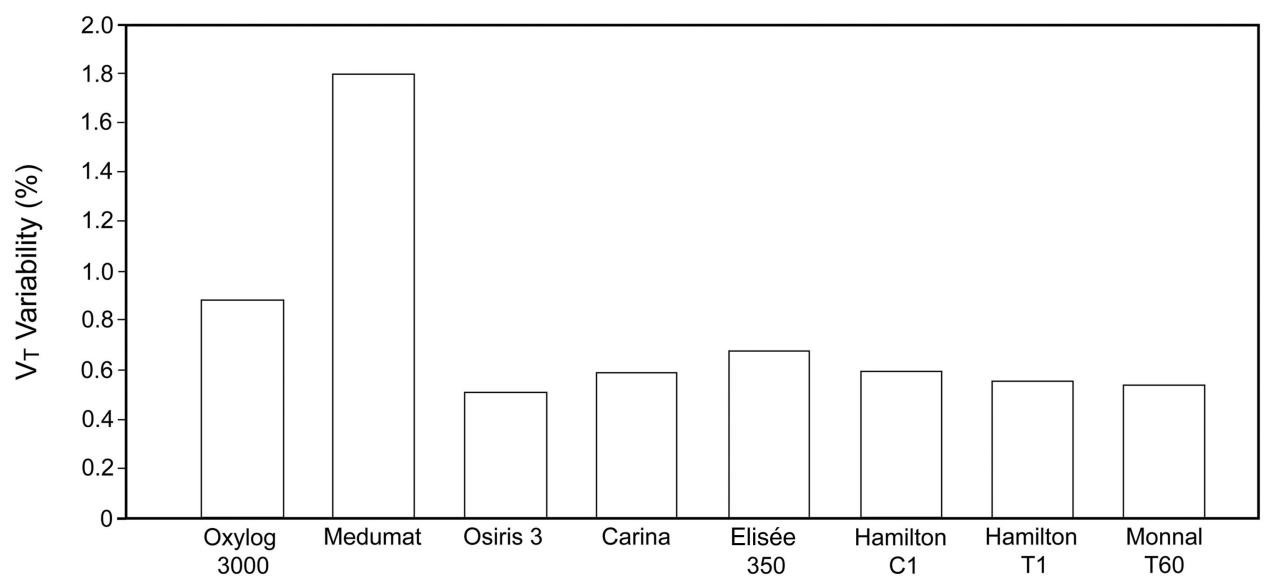

Fig. 5. Breath-to-breath tidal volume $\left(\mathrm{V}_{\mathrm{T}}\right)$ variability after averaging all mechanical conditions. 


\section{Evaluation of Ventilators Used During Transport of Critically Ill Patients}
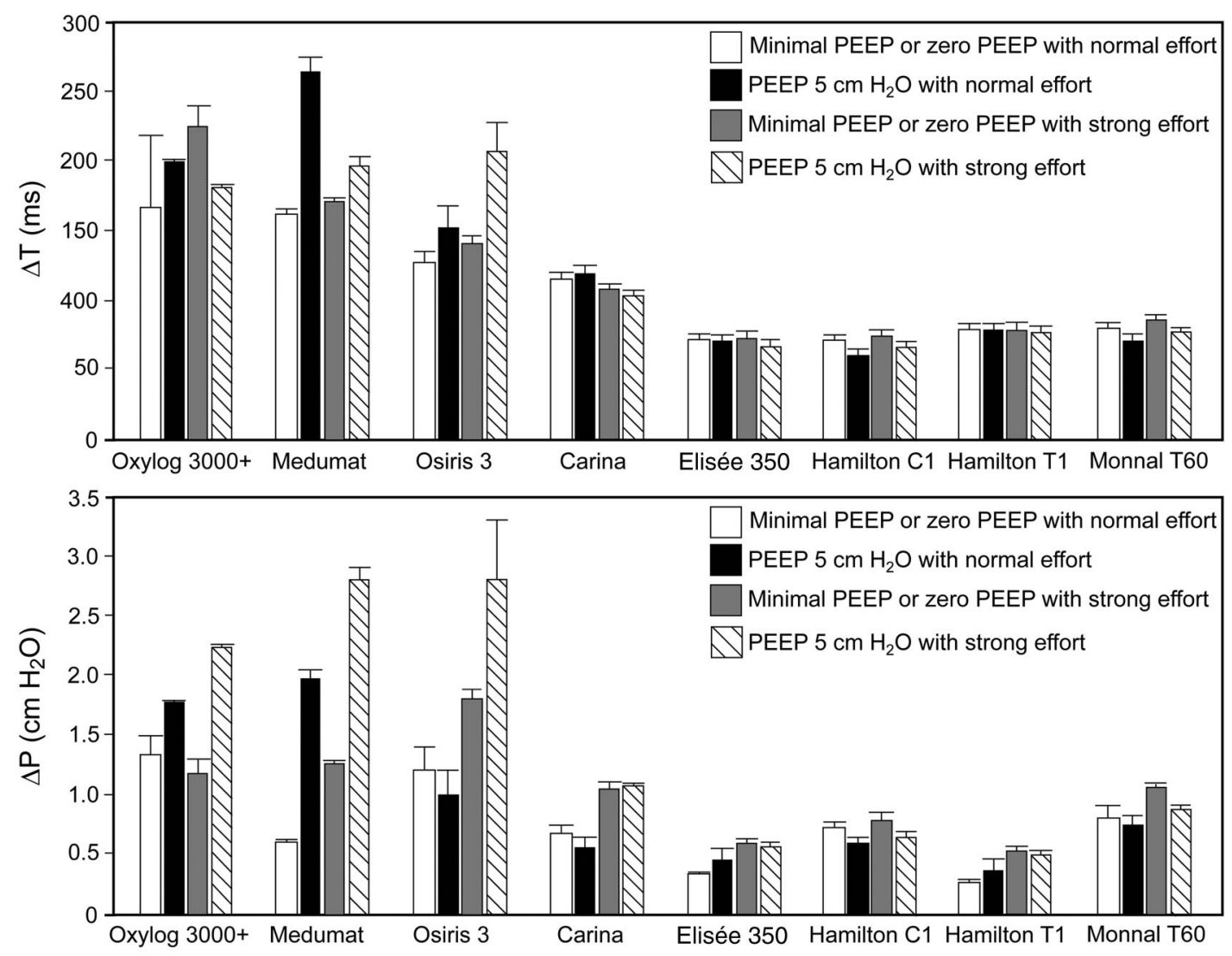

Fig. 6. Triggering performance (time delay after start of inspiration $[\Delta T]$ and pressure change $[\Delta P]$ required to trigger) of 7 transport ventilators, with either normal inspiratory effort or strong inspiratory effort, and with either the lowest available PEEP or PEEP of $5 \mathrm{~cm} \mathrm{H}_{2} \mathrm{O}$. The whisker bars represent the $99 \%$ confidence intervals.

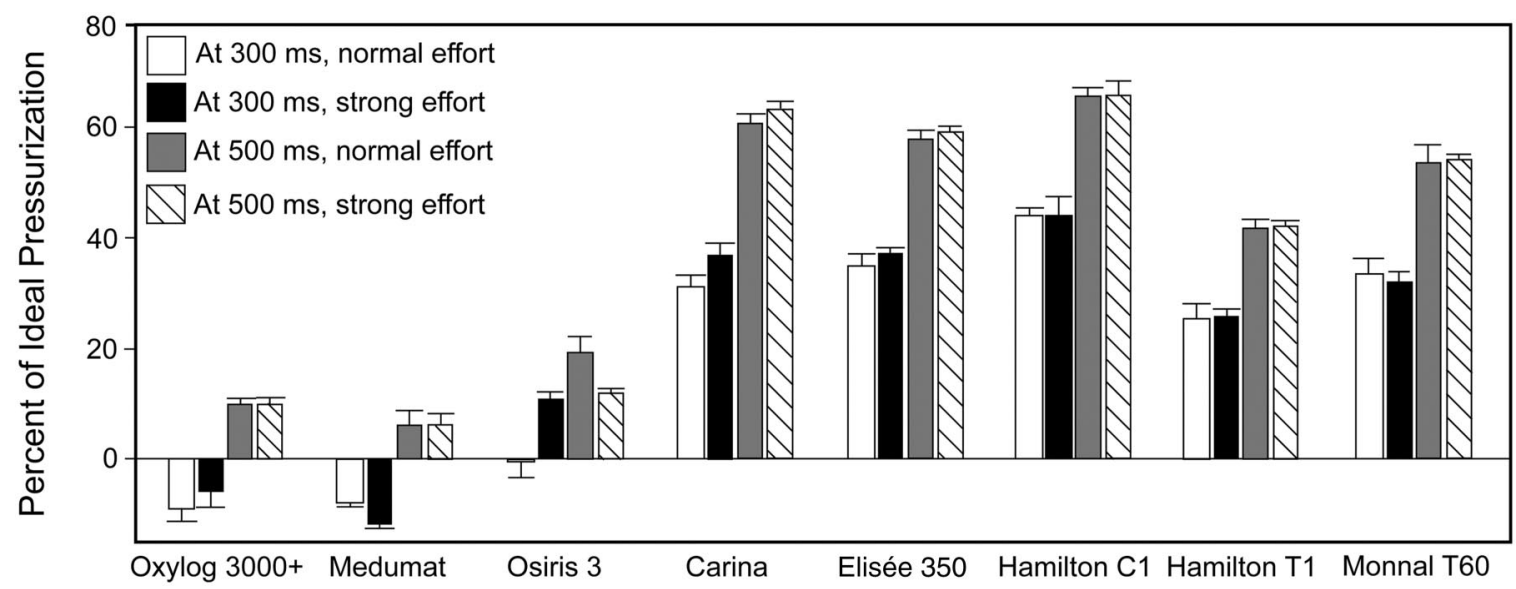

Fig. 7. Percentage of the ideal pressurization, computed as the area under the pressure-time curve at $300 \mathrm{~ms}$ and $500 \mathrm{~ms}$, with normal inspiratory effort $\left(2 \mathrm{~cm} \mathrm{H}_{2} \mathrm{O}\right)$ or strong inspiratory effort $\left(4 \mathrm{~cm} \mathrm{H}_{2} \mathrm{O}\right)$. The pairwise comparison differences are significant for all the ventilators. The whisker bars represent the $99 \%$ confidence intervals.

For the strong inspiratory effort the PTP300 ranged from $-12 \%$ to $44 \%$, and at PTP500 it ranged from $6 \%$ to $66 \%$.

Three ventilators failed to pressurize correctly in the first $0.3 \mathrm{~s}$, with a negative PTP300, in both inspiratory- effort conditions: Oxylog 3000+, Medumat, and Osiris 3. We note that the PTP300, expressed as a percentage of ideal pressurization, was always smaller than the PTP500. This was due to the initial triggering phase. 


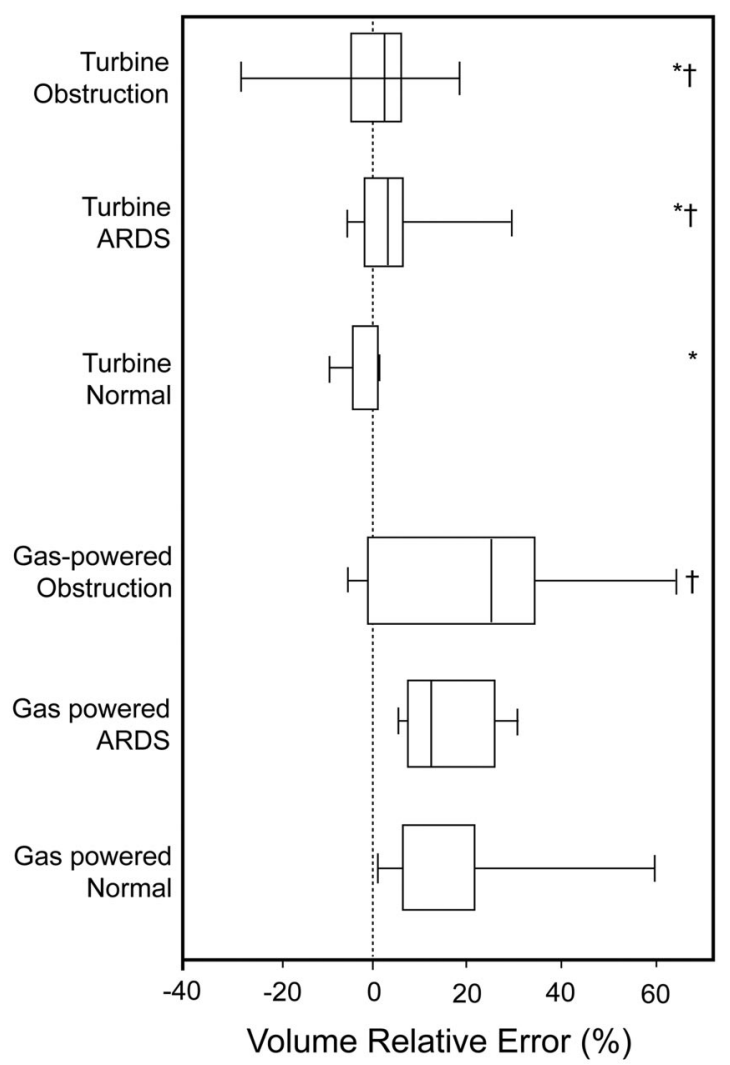

Fig. 8. Tidal volume error averaged for all tidal volume measurements in the respiratory conditions (normal, ARDS, and obstruction). In each data bar the vertical line represents the median, the left and right edges of the bars represent the 25th and 95th percentiles, and the whisker bars represent the $99 \%$ confidence intervals. ${ }^{*} P<.05$ for gas powered versus turbine ventilators. $\dagger P<.05$ versus the normal respiratory condition.

\section{Comparison Between Gas Powered and Turbine Ventilators}

In each condition the turbine ventilators were significantly more accurate in delivering the set $\mathrm{V}_{\mathrm{T}}$ (Fig. 8). Considering triggering performance, the turbine ventilators were significantly faster and more sensitive than the gas powered ventilators. Figure 9 compares the averaged PTPs for the turbine versus gas powered ventilators. There was a significant difference in PTP300 and PTP500 between the turbine ventilators and the gas powered ventilators, and between PTP300 and PTP500 in both groups of ventilators (Fig. 10).

\section{Discussion}

Our main findings are:

- $\mathrm{V}_{\mathrm{T}}$ delivery was better achieved by the turbine ventilators than the pneumatic ventilators.

- The trigger system tests were comparable to ICU and

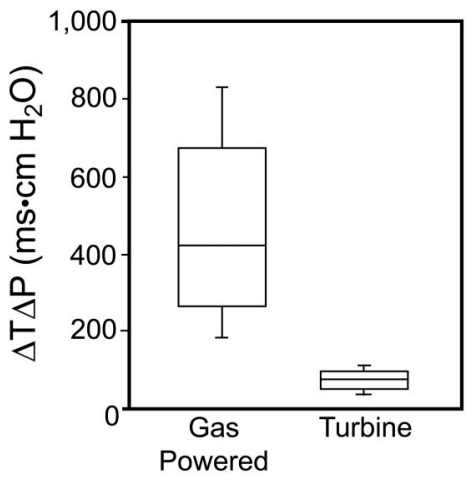

Fig. 9. Averaged pressure-time product values for the gas powered versus the turbine ventilators. In the data bars the horizontal line represents the median, the top and bottom edges of the bars represent the 25th and 95th percentiles, and the whisker bars represent the $99 \%$ confidence intervals. ${ }^{*} P<.001$ for the gas powered versus turbine ventilators.

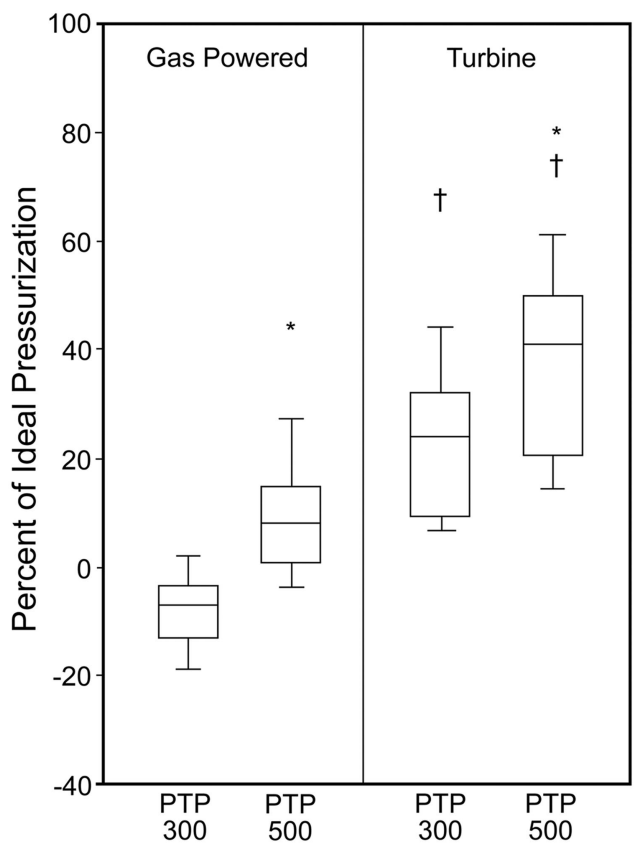

Fig. 10. Percentage of the ideal pressurization (as in Figure 7) in the gas powered versus turbine ventilators. PTP $=$ pressure-time product, at either $300 \mathrm{~ms}$ or $500 \mathrm{~ms}$. In each data bar the horizontal line represents the median, the top and bottom edges of the bars represent the 25th and 95th percentiles, and the whisker bars represent the $99 \%$ confidence intervals. ${ }^{*} P<.05$ for the gas powered versus turbine ventilators. $† P<.05$ for PTP300 versus PTP500.

home-care ventilators for all the turbine ventilators. All the pneumatic ventilators had poorer trigger performance.

- $\mathrm{V}_{\mathrm{T}}$ delivery, trigger function, and pressurization varied substantially during both volume controlled and PSV mode. 


\section{Evaluation of Ventilators Used During Transport of Critically Ill Patients}

\section{Tidal Volume}

The $\mathrm{V}_{\mathrm{T}}$ was not perfectly delivered in the normal condition by 3 ventilators: Hamilton T1, Medumat, and Osiris 3 . All the others had a $<5 \%$ average $\mathrm{V}_{\mathrm{T}}$ error. But the Hamilton $\mathrm{T} 1$ was unable to deliver an accurate $\mathrm{V}_{\mathrm{T}}$ of $300 \mathrm{~mL}$ in the low compliance and resistance condition, although the manufacturer claims that it can be used for pediatric patients. The delivered $\mathrm{V}_{\mathrm{T}}$ was too high $(430 \mathrm{~mL}$ instead of $300 \mathrm{~mL}$ ). Pediatric patients usually have high compliance and need low $\mathrm{V}_{\mathrm{T}}(<300 \mathrm{~mL})$.

With $\mathrm{V}_{\mathrm{T}}$ preset at $6 \mathrm{~mL} / \mathrm{kg}$ of predicted body weight, a $17 \% \mathrm{~V}_{\mathrm{T}}$ error represents an error of $1 \mathrm{~mL} / \mathrm{kg}$. ${ }^{9}$ Thus, the $\mathrm{V}_{\mathrm{T}}$ error range can be $1-3 \mathrm{~mL} / \mathrm{kg}$ with the ventilators we tested. The clinical implication of this finding is unclear. In ARDS patients, for example, setting an accurate $V_{T}$ is crucial, to avoid alveolar damage, despite the most recent studies on $\mathrm{V}_{\mathrm{T}}$ in ARDS that found no mortality difference between $7 \mathrm{~mL} / \mathrm{kg}$ and $10 \mathrm{~mL} / \mathrm{kg} .{ }^{10-12}$ Clearly, transport ventilators are not designed or usually used to ventilate patients with ARDS for prolonged durations, but, rather, for short transport times. However, delivered $\mathrm{V}_{\mathrm{T}}$ above $6 \mathrm{~mL} / \mathrm{kg}$ could be deleterious in the acute phase of ARDS. Some of the ventilators tested in this study appear to be more accurate and could be used safely in patients where $\mathrm{V}_{\mathrm{T}}$ control is paramount. The turbine ventilator Elisée 350 did not deliver an accurate $\mathrm{V}_{\mathrm{T}}$ in the ARDS condition (variations of $>10 \%$ ). We do not have a clear explanation for this last finding. One reason could be the duration of the inspiratory pause, which could be too short. Consequently, the algorithm used the dynamic compliance to set the $\mathrm{V}_{\mathrm{T}}$, and not the static compliance. This finding is consistent with a previous study, ${ }^{9}$ which showed that when the user applied an inspiratory pause during the inspiratory phase, the $\mathrm{V}_{\mathrm{T}}$ was decreased with some ventilators.

In the obstructive condition only 4 ventilators (Elisée 350, Monnal T60, Hamilton T1, and Oxylog 3000+) could manage heavy mechanical load at the $800 \mathrm{~mL} \mathrm{~V}_{\mathrm{T}}$ and deliver an accurate $\mathrm{V}_{\mathrm{T}}$. All the others had $\mathrm{V}_{\mathrm{T}}$ error of $>10 \%$.

Two of the turbine ventilators showed dysfunctions in certain test conditions: ARDS condition with the Elisée 350, and normal condition at low $\mathrm{V}_{\mathrm{T}}$ with the Hamilton $\mathrm{T} 1$. This suggests that there is some problem with the software. Apart from these specific dysfunctions, the turbine ventilators had more accurate $\mathrm{V}_{\mathrm{T}}$ delivery than the pneumatic ventilators in all the test conditions.

\section{Triggering}

The triggering performance was heterogeneous among the ventilators. The gas-powered ventilators had relatively long triggering delay and poor pressure sensitivity. The turbine ventilators had more sensitive triggering, compa- rable to ventilators designed for home care ${ }^{8}$ and ICU use. ${ }^{13,14}$ The Monnal T60 showed auto-triggering at the highest triggering sensitivity setting in a first study, but that was corrected by new software. A short triggering time $(<100 \mathrm{~ms})$ may be associated with a lower work of breathing, ${ }^{15}$ is below the conscious threshold of inspiratory effort, ${ }^{16}$ and may improve patient-ventilator synchrony. ${ }^{17-19}$ All the turbine ventilators had a trigger time shorter than $100 \mathrm{~ms}$, even with the weak inspiratory effort.

\section{Pressurization Performance}

We found that airway pressure remained negative for more than $0.3 \mathrm{~s}$ with the Medumat and Oxylog 3000+, during which they would not unload the patient's inspiratory effort, which could increase patient work of breathing. If we consider the percentage of ideal pressurization, we found no dependence of PTP300 or PTP500 on the pressure support level, PEEP, or inspiratory effort. All the turbine ventilators unloaded the simulated patient quite quickly and with adequate pressure.

A previous study 20 found that ICU turbine ventilators were no better than gas powered ones in PSV mode. Our evaluation of transport ventilators did not reach the same conclusion. Clearly, for triggering and pressurization performance the latest generation of turbine powered transport ventilators outperformed the pneumatic models.

\section{Synthesis}

We can divide the tested ventilators in 3 categories. The first one includes the Carina, Elisée 350, Hamilton C1, Hamilton T1, and Monnal T60, which had good performance in both the static and dynamic tests. The second category includes the Osiris 3 and Medumat, which had poorer performance in both the static and dynamic tests. The third category includes only the Oxylog 3000+, which has good performance in the static tests but poor performance in the dynamic tests. The Oxylog 3000+, Osiris 3, and Medumat are gas powered ventilators.

Comparisons between the gas powered and turbine ventilators with regard to $\mathrm{V}_{\mathrm{T}}$ accuracy, triggering, and pressurization show a significant superiority of turbine ventilators. These results suggest that turbine technology is a breakthrough in transport ventilators, allowing for better performance. Almost all of the turbine ventilators have improved their battery duration. Advances in battery duration and miniaturization allow the use of turbine ventilators for long-term transport.

\section{Comparison With Other Studies}

In comparison with ICU ventilators, ${ }^{2,9}$ some of the turbine transport ventilators and the Oxylog $3000+$ performed 


\section{Evaluation of Ventilators Used During Transport of Critically Ill Patients}

as well as modern ICU ventilators in volume controlled mode. The Monnal T60 had the same performance as the most efficient ICU ventilators, as reported in other studies. ${ }^{9}$ Many transport ventilators outperform home-care ventilators in $\mathrm{V}_{\mathrm{T}}$ accuracy. ${ }^{21}$ However, the remaining ventilators did not perform as well (high airway resistance with almost all of them, ARDS with high airway resistance with the Elisée 350). One should be aware of these limitations when using this category of ventilator. By comparison with older transport ventilators, 2,22 we note a substantial improvement in accuracy in volume controlled modes.

In PSV mode, comparisons with ICU or anesthesia ventilators, ${ }^{2,13,14,23}$ home-care ventilators, ${ }^{8,24}$ mid-level ICU ventilators, ${ }^{25}$ and older-generation transport ventilators ${ }^{2}$ show that all the turbine ventilators tested in this study had performance comparable to ICU ventilators. In the dynamic conditions, several ventilators were comparable to ICU or home-care ventilators, and had better performance than older-generation ICU ventilators. On the other hand, the most recent pneumatic transport ventilators behave like prior generations, suggesting that we may have reached a limit in this technology.

\section{Limitations}

The limitations of such bench studies are discussed in other works. The main one is that the study is performed on a bench test rather than with patients. Patient comfort and gas exchange are particularly important, and these are not tested in the bench study. The choice of a transport ventilator depends on several other parameters, such as the modes available, the possibility of monitoring end-tidal $\mathrm{CO}_{2}$, ergonomics, and the quality of graphics. ${ }^{26}$ However, bench studies are important to assess the mechanical performance of ventilators before clinical use.

Another limitation is that the durability of these ventilators was not tested. This problem is particularly important in pre-hospital care, where repeated mechanical shocks could damage the device. Finally, we did not thoroughly describe the auto-triggering phenomenon, and some of the ventilators showed auto-triggering in the triggered modes. We are not able to identify whether this unstable behavior was real or an artifact due to the rebound of the test lung on the metal clip that linked the 2 lung compartments.

\section{Conclusions}

The performance of the tested transport ventilators was heterogeneous in $\mathrm{V}_{\mathrm{T}}$ delivery and during simulated spontaneous ventilation. Some of the ventilators, particularly the turbine ventilators, showed good performance, comparable to ICU ventilators, suggesting that they could improve the safety of critically ill patients during transport. These results suggest that turbine ventilators have better performance. Other studies should be performed to assess clinical benefits and to assess the ergonomics of these devices.

\section{ACKNOWLEDGMENTS}

We are grateful to Dani Marino and Laurence Boiron for editing assistance.

\section{REFERENCES}

1. Waydhas C. Intrahospital transport of critically ill patients. Crit Care 1999;3(5):R83-R89.

2. Zanetta G, Robert D, Guerin C. Evaluation of ventilators used during transport of ICU patients: a bench study. Intensive Care Med 2002; 28(4):443-451.

3. Chipman DW, Caramez MP, Miyoshi E, Kratohvil JP, Kacmarek RM. Performance comparison of 15 transport ventilators. Respir Care 2007:52(6):740-751.

4. Miyoshi E, Fujino Y, Mashimo T, Nishimura M. Performance of transport ventilator with patient-triggered ventilation. Chest 2000; 118(4):1109-1115.

5. McGough EK, Banner MJ, Melker RJ. Variations in tidal volume with portable transport ventilators. Respir Care 1992;37(3):233-239.

6. Nakamura T, Fujino Y, Uchiyama A, Mashimo T, Nishimura M. Intrahospital transport of critically ill patients using ventilator with patient-triggering function. Chest 2003;123(1):159-164.

7. Berger KI, Sorkin IB, Norman RG, Rapoport DM, Goldring RM. Mechanism of relief of tachypnea during pressure support ventilation. Chest 1996;109(5):1320-1327.

8. Battisti A, Tassaux D, Janssens JP, Michotte JB, Jaber S, Jolliet P. Performance characteristics of 10 home mechanical ventilators in pressure-support mode: a comparative bench study. Chest 2005; 127(5):1784-1792.

9. Lyazidi A, Thille AW, Carteaux G, Galia F, Brochard L, Richard JC. Bench test evaluation of volume delivered by modern ICU ventilators during volume-controlled ventilation. Intensive Care Med 2010; 36(12):2074-2080

10. Brochard L, Roudot-Thoraval F, Roupie E, Delclaux C, Chastre J, Fernandez-Mondéjar E, et al. Tidal volume reduction for prevention of ventilator-induced lung injury in acute respiratory distress syndrome. The Multicenter Trail Group on Tidal Volume reduction in ARDS. Am J Respir Crit Care Med 1998;158(6):1831-1838.

11. Brower RG, Shanholtz CB, Fessler HE, Shade DM, White P Jr, Wiener $\mathrm{CM}$, et al. Prospective, randomized, controlled clinical trial comparing traditional versus reduced tidal volume ventilation in acute respiratory distress syndrome patients. Crit Care Med 1999;27(8):1492-1498.

12. Stewart TE, Meade MO, Cook DJ, Granton JT, Hodder RV, Lapinsky SE, et al. Evaluation of aventilation strategy to prevent barotrauma in patients at high risk for acute respiratory distress syndrome. Pressure- and Volume-Limited Ventilation Strategy Group. N Engl J Med 1998 338(6):355-361.

13. Richard JC, Carlucci A, Breton L, Langlais N, Jaber S, Maggiore S, et al. Bench testing of pressure support ventilation with three different generations of ventilators. Intensive Care Med 2002;28(8):1049-1057.

14. Jaber S, Langlais N, Fumagalli B, Cornec S, Beydon L, Harf A, et al. [Performance studies of 6 new anesthesia ventilators: bench tests]. Ann Fr Anesth Reanim 2000;19(1):16-22. Article in French

15. Aslanian P, El Atrous S, Isabey D, Valente E, Corsi D, Harf A, et al. Effects of flow triggering on breathing effort during partial ventilatory support. Am J Respir Crit Care Med 1998;157(1):135-143.

16. Whitelaw WA, Derenne JP, Milic-Emili J. Occlusion pressure as a measure of respiratory center output in conscious man. J Respir Physiol 1975;23(2):181-199. 
17. Thille AW, Rodriguez P, Cabello B, Lellouche F, Brochard L. Patient-ventilator asynchrony during assisted mechanical ventilation. Intensive Care Med 2006;32(10):1515-1522.

18. Racca F, Squadrone V, Ranieri VM. Patient-ventilator interaction during the triggering phase. Respir Care Clin N Am 2005;11(2):222-245.

19. Sassoon CSH, Mahutte CK, Te TT, Simmons DH, Light RW. Work of breathing and airway occlusion pressure during assist-mode mechanical ventilation. Chest 1988;93(3):571-576.

20. Thille AW, Lyazidi A, Richard JC, Galia F, Brochard L. A bench study of intensive-care-unit ventilators: new versus old and turbinebased versus compressed gas-based ventilators. Intensive Care Med 2009;35(8):1368-1376.

21. Lofaso F, Fodil R, Lorino H, Leroux K, Quintel A, Leroy A, et al. Inaccuracy of tidal volume delivered by home mechanical ventilators. Eur Respir J 2000;15(2):338-341.
22. Nolan JP, Baskett PJ. Gas-powered and portable ventilators: an evaluation of six models. Prehosp Disaster Med 1992;7(1):25-34

23. Jaber S, Tassaux D, Sebbane M, Pouzeratte Y, Battisti A, Capdevila $\mathrm{X}$, et al. Performance characteristics of five new anesthesia ventilators and four intensive care ventilators in pressure-support mode: a comparative bench study. Anesthesiology 2006;105(5):944-952.

24. Tassaux D, Strasser S, Fonseca S, Dalmas E, Jolliet P. Comparative bench study of triggering, pressurization, and cycling between the home ventilator VPAP II and three ICU ventilators. Intensive Care Med 2002;28(9):1254-1261.

25. Ferreira JC, Chipman DW, Kacmarek RM. Trigger performance of mid-level ICU mechanical ventilators during assisted ventilation: a bench study. Intensive Care Med 2008;34(9):1669-1675.

26. Branson RD, Johannigman JA. The role of ventilator graphics when setting dual-control modes. Respir Care 2005;50(2):187-201. 